\title{
Talent: A contestable, but not contested, concept?
}

\section{Response to commentaries}

\author{
Joseph Baker ${ }^{1} \&$ Nick Wattie ${ }^{1, *}$ \\ 1 Lifespan Health and Performance Laboratory, York University, Toronto, Canada \\ 2 Faculty of Health Sciences, Ontario Tech University, Oshawa, Canada \\ * Corresponding author: Faculty of Health Sciences, 2000 Simcoe Street North, Ontario Tech University, Oshawa, Canada \\ Tel: +1 9057218668 ext 2248 \\ E-Mail: nick.wattie@uoit.ca
}

\section{TA ARTICEL}

\section{Article History:}

Submitted $15^{\text {th }}$ May 2019

Accepted $15^{\text {st }}$ June 2019

Published $12^{\text {th }}$ November 2019

Handling Editor:

Lisa Steidl-Müller,

University of Innsbruck, Austria

Editor-in-Chief:

Martin Kopp

University of Innsbruck, Austria

\section{ABSTRACT}

Our target article on 'Innate talent' had two objectives, first to acknowledge the 20th anniversary of the seminal contribution by Howe, Davidson and Sloboda (1998) and second, to update this information as it relates to talent in the domain of sport. Many thanks to all the authors that took the time to provide commentaries on our review. Broadly, our target paper focused on 1) whether the concept of innate talent was reasonable and scientifically sound and 2) whether the concept of innate talent had any utility to those working at the coalface of sport science (e.g., coaches, scouts, etc.). All of the commentaries were complimentary to our review, which suggested continued interest in this area (although this was noted as surprising by Hambrick and Burgoyne). We have tried to respond to all of the interesting points raised by the commentaries, but this was not always possible. That said, we grouped our responses under general themes below. Our impression, based on the commentaries, is that innate talent is not a contested concept; in that there appears to be agreement (for the most part) that, 'this thing exists'. Rather, the concept of innate talent is contestable (Gallie, 1956); that is, there is debate about exactly what it is, the degree of its influence, and how useful the concept of innate talent is.

Keywords:

Talent - sport - nature nurture debate - expertise - athlete development

Citation:

Baker, J. \& Wattie, N. (2019). Talent: A contestable, but not contested, concept? Response to commentaries. Current Issues in Sport Science, 4:108. doi: 10.36950/CISS_2019.108.

Baker, J. \& Wattie, N. (2018). Innate talent in sport: Separating myth from reality. Current Issues in Sport Science, 3:006. doi: 10.36950/ CISS_2018.006

\section{What is talent?}

One of the themes that emerged from multiple commentaries related to 'what talent is'. Some of the authors used a different set of nomenclature than we did, and multiple authors emphasized the need to conceptualize talent as the combination of genetic and environmental factors.

The purpose of our paper was certainly not to pit nature vs. nurture (as implied by the title of Hambrick and Burgoyne's commentary: "Beyond nature vs. nurture in expertise research").
Indeed, in our critique of Howe et al.'s Criteria 5, we state that predisposition and innate capacity (innate talent), combined with time and training, are necessary for attainment expert performance in sport. Moreover, in the opening paragraph of our section, the concept of innate talent is valid, we state that,

"the premise of innate talent as a concept does not have to rely on a dichotomized or deterministic conceptualization (i.e., that innate talent is the sole determinant of sport expertise), but rather, there may be evidence supporting varying degrees of innate talent, where talent exists on a continuum." 
We speculate that one of the casualties of arguing (necessarily) against nature-nurture dichotomies, may be a lack of detailed discussions about nature (innate talent) and nurture (practice/ the environment). This may be one of the reasons for the lack of agreement on an operational definition of 'talent' noted below. Have we, as a field, spent a disproportionate amount of time and effort arguing against false dichotomies, rather than striving for conceptual clarity about nature and nurture? We agree with Hambrick and Burgoyne that we should be far beyond nature vs. nurture dichotomies in expertise research, but we do not feel that the concept of innate talent is synonymous with this dichotomy. The concept of innate talent can exist alongside the view that expertise results from interactions between nature and nurture. As such, we need discussions about innate talent because at a basic level we still lack consensus on what talent is. The need for consensus and rigour is real. Despite theoretical and empirical limitations to our understanding of talent, as we note in our review, people, policies, and youth sport structures act in ways that are consistent with notions of 'innate' talent; the horse is out of the barn.

The challenge of achieving conceptual clarity is complicated by the fact that discussions of innate talent necessarily intersect with multiple disciplines. For example, Rommers and Rössler suggest that "Talent is a concept that is hard to define, but it generally refers to mastery of certain skills (Gagne, 1995). The term talent is often used when talking about gifted young athletes, who might have the potential to develop into future professionals and high performers (later in life)... we will use the term gifted to describe athletes who have the potential to make it into professional athletes, which the term 'talent' refers to the best performing athletes at that current moment." Here Rommers and Rössler seem to have simply substituted 'gifted' for 'talent', otherwise they seem in agreement that the concept of innate talent has utility.

Similarly, Davids and Araújo describe talent as process of "internal dynamics", specifically as "underlying tendencies, dispositions and capacities related to successful performance in specific domains which may signal future potential for individual functionality". Faber noted that any account of talent is dependent on the particular context (sport-specific and historical), and some degree of chance. Again, none of these authors disagree with our position regarding the validity of innate talent as a concept. However, they emphasize the need for better conceptual clarity about the properties of talent in sport, an issue we have explored elsewhere (Baker, Wattie, \& Schorer, 2019).

\section{Does the concept have real world utility?}

Another common theme in the commentaries concerned the real world value of this notion of talent. While we and the commentators mostly agree the concept is reasonable, that does not mean it is useful, at least as it is currently defined. On the one hand, we agree with Rommers and Rössler that most approaches to talent selection are inherently flawed because they do not recognize the enormous complexity involved in athlete development. This runs counter to the arguments put forth by Romann as well as Hambrick and Burgoyne regarding the obvious value of heritable qualities like aerobic capacity or proportion of fast versus slow twitch muscle fibres. It is important here to highlight that while heritability estimates (i.e., such as those highlighting the high heritability of physiological outcomes) are useful when understanding populations of athletes, these same estimates have very little utility at the individual level because a) genetically constrained factors are also affected by the environment (e.g... it is not possible to take an athlete's performance/function at a single point in time and partial out the role of training on this outcome), b) phenotypic outcomes are determined by numerous genes (e.g., thousands of genetic variants have been associated with height, Yang et al., 2010), and c) our ability to identify these genes is problematic at best (e.g., Webborn et al., 2015).

On the other hand, if we agree that talent is a reasonable concept, approaches to talent selection and development need to be updated to recognize this complexity and, more importantly, the limits of a linear, unidimensional focus. As Rommers and Rössler note, "a 'one size fits all' consensus for talent identification in sports is not possible". We agree and appreciate the non-linear dynamics approach advocated by Davids and Araujo. This is a strong framework for understanding and discussing the myriad factors dynamically interacting to affect athlete's performance and development. Their notion of 'adaptive flexibility' has important implications for coaching, training and the development of more appropriate models of longterm athlete development. However, key biological constraints (again, height being the most obvious) could ultimately limit the extent to which the developing athlete 'system' is able to be flexible in meeting performance and competition demands. Biological predispositions, however they manifest, will limit the range of opportunities available to each performer and unfortunately there is evidence that these constraints are getting harder to overcome. For instance, as sports have evolved, morphological factors have become more homogeneous (Norton \& Olds, 2001). In basketball players have gotten taller (especially centers), but more remarkably, they have gotten larger (i.e., increased stature). These changes will constrain the opportunities for individuals without predispositions for above average height and body size. This is not to suggest that we should select athletes based solely on morphological predictions; it takes more than size to be a successful athlete and sports are constantly evolving. Height is simply used here as the most obvious example of how genotype affects phenotype. However, it is important to move away from models of influence where talent is seen as 'innate, fixed and immutable' as suggested by Romann. Importantly, 'innate' does not mean fixed and immutable. This view of talent belongs in the past. Current research emphasizes genes influence our development in a way that is dynamic, based on our experiences and the opportunities provided by our environment. 


\section{Moving Forward}

A number of commentaries discussed issues related to how this field should move forward. One of the recurring topics related to the indicators or measures of talent. Faber noted that height is not always a predictor for all sports (pg. 3 "the validness of innate talent concerning anthropometric predisposition might not hold in all sports"), a point we completely agree with. Here, height was used as an example of a variable that is highly heritable and obviously important in some sports. Faber also proposes that importance of anthropometric characteristics like height may be overestimated "due to selection policies and the developmental system used in youth sport". While maturation-selection does indeed play an important role during youth sport, the leap to suggest that it is not a component of talent does not seem warranted. In fact, there is evidence that the importance of anthropometric characteristics (including factors other than height) has been increasing at elite levels of sport: In sports where height is valuable to performance, elite athletes have gotten taller over time (the inverse is also true). In sports where size is important, athletes have gotten larger. It is unlikely that this 'expanding universe of bodies' (see Norton \& Olds, 2001) is independent of the task constraints within sports at the highest level, and simply the result of temporary advantages in youth sport. We wonder which came first, the specialization of bodies at elite levels or the specialization of bodies at youth levels? We would think the former.

Hambrick and Burgoyne were surprised by our claim "with the exception of a few variables related to body size, no robust indicators of talent currently exist" and highlight the various physiological characteristics that have high heritability (e.g., aerobic capacity). If we know a certain variable is important (e.g., aerobic capacity, work ethic, etc.) then why can't we just select for this variable? As we've noted above, this view is too simplistic for several reasons. First, performance in most sports is the result of a complex interaction of variables (e.g., endurance sports require a high aerobic capacity and high levels of running economy, Shaw, Ingham, Atkinson, \& Follard, 2015) and talent selectors would not want to rely on a single variable to capture talent, even if reliable and valid indicators exist. Second, talent selection usually involves making selections between highly skilled athletes and slightly less skill athletes, which is profoundly more difficult than comparing athletes to non-athletes. In short, to us aerobic capacity is an excellent example to support our conclusion that the concept of talent is reasonable, but currently has limited practical utility.

Hambrick and Burgoyne also point to the fact that general intelligence $(' g$ ') is a reliable correlate of expertise in a range of other domains, and suggest that it may be a worth exploring with respect to sport expertise. This is interesting but prior work on cognitive function (i.e., general executive functions, working memory: see Buszard, Masters, \& Farrow, 2017; Farrow, Reid, Buszard, \& Kovalchik, 2018; Vestberg, Gustafson, Maurex, Ingvar, \& Petrovic, 2012) and performance in sport has been equivocal. We suspect that this may be due to the fact that talent is "a multidimensional construct that cannot be aggregated to a single score and is comprised from different combinations of different abilities" (p.4) There are different ways of being talented; talent reflects different permutations and combinations of characteristics, which also differ by sport: see Baker, Wattie, \& Schorer, 2019).

Given the complexity of talent as a concept, and of navigating potential indicators of talent, there are considerable challenges moving forward, for scientists and practitioners. The commentaries highlight the need to understand the different ways of being talented on a sport-specific basis. They also stress the need to better understand the ways environmental factors (including pedagogical approaches) interact with innate characteristics. The challenges are significant. We argue (as do some of the commentaries) that the gap between where we are and where we need to be, renders the concept of innate talent unusable. Certainly, practitioners, parents and athletes should be made aware of the fruitlessness of genetic testing for identifying and developing talented athletes; the scientific consensus on these products and services is that they should be avoided (Webborn et al., 2015).

Given the lack of consensus on what constitutes talent, or what the conceptual elements of talent are, there is also clearly a need to discuss these issues. Elsewhere, we have proposed some features of innate talent (Baker, Wattie, \& Schorer, 2019). However, these features, and those proposed by others, need to be reviewed, evaluated and revised. Much work needs to be done. Finally, we believe that there is real value in the targetarticle-commentary format for stimulating ideas and debates about important topics, and hope to see this format used more frequently going forward.

\section{Funding}

The authors have no funding or support to report.

\section{Competing Interests}

The authors have declared that no competing interests exist.

\section{Data Availability Statement}

All relevant data are within the paper.

\section{References}

Baker, J., Wattie, N., \& Schorer, J. (2019). A proposed conceptualization of talent in sport: The first step in a long and winding road. Psychology of Sport \& Exercise, 43, 27-33. 
Buszard, T., Masters, R.S.W., \& Farrow, D. (2017). The generalizability of working-memory capacity in the sport domain. Current Opinion in Psychology, 16, 54-57.

Farrow, D., Reid, M., Buszard, T., \& Kovalchik, S. (2018). Charting the development of sport expertise: Challenges and opportunities. International Review of Sport and Exercise Psychology, 11, 238-257.

Gallie, W.B. (1956). Essentially contested concepts. Proceedings of the Aristotelian Society, 56, 167-198.

Norton, K. \& Olds, T. (2001). Morphological evolution of athletes over the $20^{\text {th }}$ century. Sports Medicine, 31, 763-783

Shaw, A.J., Ingham, S.A., Atkinson, G., \& Follard,J.P. (2015). The correlation between running economy and maximal oxygen uptake: Cross-sectional and longitudinal relationships in highly trained distance runners. PLOS ONE, 10, e0123101

Vestberg, T., Gustafson, R., Maurex, L., Ingvar, M., \& Petrovic, P. (2012). Executive functions predict the success of top soccer players. PLoS ONE, 7, e34731.

Webborn, N., Williams, A., McNamee, M., Bouchard, C., Pitsiladis, Y., Ahmetov, I., ... \& Dijkstra, P. (2015). Direct-to-consumer genetic testing for predicting sports performance and talent identification: Consensus statement. British Journal of Sports Medicine, 49(23), 1486-1491.

Yang, J., Benyamin, B., McEvoy, B. P., Gordon, S., Henders, A. K., et al. (2010). Common SNPs explain large proportion of the heritability for human height. Nature Genetics, 42, 565-569. 